\title{
Especificidade de Puccinia pampeana a cultivares de Capsicum spp. e outras solanáceas
}

\author{
Martha Maria Passador ${ }^{1,2 *}$, Edson Luiz Furtado ${ }^{1}$ Mário Barreto Figueiredo²
}

${ }^{1}$ Departamento de Produção Vegetal, Faculdade de Ciências Agronômicas - UNESP, CEP-18.610-307, Botucatu-SP; ${ }^{2}$ Instituto Biológico de São Paulo, Centro de Pesquisa e Desenvolvimento de Sanidade Vegetal, Laboratório de Micologia Fitopatológica. *Parte da Dissertação de Mestrado do primeiro autor: Bolsista do CNPq

Autor para correspondência: Martha Maria Passador marthamaria_p@yahoo.com.br

Data de chegada: 10/07/2007. Aceito para publicação em: 09/01/2008.

1498

\section{RESUMO}

Passador, M.M.; Furtado, E.L.; Figueiredo, M.B. Especificidade de Puccinia pampeana a cultivares de Capsicum spp. e outras solanáceas. Summa Phytopathologica, v.35, n.1, p.63-67, 2009

A ferrugem de espécies de Capsicum spp. (pimenta e pimentão), é causada pelo fungo Puccinia pampeana, pode causar perdas totais em plantios de diversas espécies de Capsicum, onde preodminam temperaturas ao redor de $21^{\circ} \mathrm{C}$. Esta ferrugem, mesmo sendo específica do gênero Capsicum, e mesmo muitas espécies dentro deste gênero sendo suscetíveis, algumas apresentam reação de hipersensibilidade. Foi o caso de Capsicum annuum (pimenta cv. Cayenne) e C. chinense (pimenta cv.
Habañero), que após a formação dos espermogônios (11 dias), apresentou manchas necróticas na região periférica aos espermogônios, aos 15 dias após a inoculação, não havendo evolução da infecção. Também foi observada reação de hipersensibilidade, de forma mais moderada em folhas C. annuum (pimenta serrano) e C. baccatum (chapéu-de-frade). Com relação às outras solanáceas inoculadas (jiló e berinjela) não foram observados os sintomas e sinais da infecção.

Palavras-chave adicionais: ferrugem de Capsicum, variedades, hipersensibilidade

\section{ABSTRACT}

Passador, M.M.; Furtado, E.L.; Figueiredo, M.B. Specificity of Puccinia pampeana to Capsicum spp. cultivars and other solanaceous plants. Summa Phytopathologica, v.35, n.1, p.63-67, 2009

The Capsicum spp. (pepper and green pepper) rust is caused by the fungus Puccinia pampeana. This is an important disease in these crops which may cause complete losses in crops of several species of Capsicum. Although specific to the genus Capsicum, and despite the fact that many species within this genus are susceptible to rust, some of them have shown a hypersensitivity reaction. That was the case with Capsicum annuum (Cayenne pepper) and C. chinense (datil pepper), which, after spermogonia formation (11 days), showed necrotic spots in the peripheral region of the spermogonia 15 days after inoculation, without evolution of the infection. A milder hypersensitivity reaction was also observed only in leaves of $C$. annuum (chili pepper) and C. baccatum (“chapéu-de-frade”). With regard to other solanaceous plants inoculated ("jiló" and eggplant), no symptoms or signs of infection were observed.

Keywords: Capsicum rust, varieties, hypersensitive reaction

A ferrugem de Capsicum spp., causada pelo fungo Puccinia pampeana ocorre na região sul e sudeste do Brasil, com maior freqüência no outono e inverno, quando predominam as temperaturas moderadas a redor de 18 e $21^{\circ} \mathrm{C}$ e alta umidade, podendo causar perdas totais das culturas que infectam. Ataca toda a parte aérea, especialmente tecidos jovens. As folhas, frutos, caule e brotos infectados sofrem hipertrofia, encarquilhamento, distorções, fasciação e superbrotamento das gemas apicais e laterais, dando origem a estruturas ou ramos laterais que crescem de forma mais ou menos indefinida, do tipo "vassoura de bruxa". Os sintomas se manifestam predominantemente nas folhas, mas também em outras partes vegetais como bainhas, flores e frutos em início de desenvolvimento (6). Sabe-se que este superbrotamento, resulta de um desequilíbrio hormonal, com acúmulo de quantidade significativa de um indutor de crescimento, provavelmente o àcido-indol-acético (AIA), hormônio vegetal considerado como a principal auxina de ocorrência natural (10).

O fungo Puccinia pampeana, tem um ciclo de vida muito raro. Após a penetração e desenvolvimento do talo monocariótico, apresenta espermogônios e espermácias, em um único hospedeiro, sendo assim denominado autoécio. A única estrutura infectiva do microrganismo é o basidiosporo, pela germinação de qualquer dos dois estados teleomórficos, originados pelo talo dicariótico $(\mathrm{N}+\mathrm{N})$ : o tipo Puccinia ou, o tipo Endophyllum (9).

Devido à existência desses dois estados teleomórficos, $P$. pampeana é caracterizado como um microrganismo biteleomórfico (4, 6, 7). Os soros do tipo Endophyllum apresentam morfologia semelhante à do anamorfo Aecidium e produzem teliosporos aecidióides (III ${ }^{\mathrm{I}}$ - teliosporos morfologicamente semelhantes à eciosporos), unicelulares, catenulados, de coloração amarelo-ouro, sem pedicelo e envoltos por uma membrana, o perídio. Os soros do tipo Puccinia surgem ao final do ciclo da doença sendo constituídos por teliosporos telióides (III) bicelulares, pedicelados e que apresentam intensa coloração marrom (8). Estes últimos são os responsáveis pela sobrevivência do fungo, sob temperaturas extremas, durante o verão. Isto porque apresentam parede espessa, com grande concentração de substância auto-inibidora da germinação, com função de impedir que todos os esporos germinem simultaneamente sob condições ambientais desfavoráveis, e assim possibilita sua permanência na planta de uma estação para outra $(5,6)$.

Como medidas de controle, ainda não existem formas eficazes, algumas medidas utilizadas no controle de outras ferrugens podem 
ser avaliadas para a ferrugem da pimenteira. O presente estudo teve como objetivos avaliar a suscetibilidade de diferentes cultivares de Capsicum spp. a P. pampeana e, a sua capacidade de infecção sobre outras solanáceas cultivadas, como jiló (Solanum gillo) e berinjela (Solanum melongena).

Foram avaliadas diferentes espécies de pimentão e pimenta, e também outras solanáceas, jiló e berinjela (Tabela 1).

A semeadura foi realizada em vasos plásticos de $10 \mathrm{~cm}$ de diâmetro e $10 \mathrm{~cm}$ de altura, contendo solo na proporção de 1:1:1 (solo/areia/substrato). Os hospedeiros desde a emergência, foram mantidos em casa de vegetação, com temperatura ambiente e irrigados duas vezes ao dia até a realização das inoculações, quando foram transferidos para câmaras de temperatura e luminosidade controladas (BOD), com temperatura entre 18 e $20^{\circ} \mathrm{C}$, e fotoperíodo de 14 horas de luz e 10 horas de escuro. Todas as plantas utilizadas estavam em média com 60 dias de semeadura, e apresentavam altura média de 20 a $35 \mathrm{~cm}$.

Para a inoculação foram utilizados esporos de isolado proveniente de pimenteiras da cultivar Bode (Capsicum chinense L.), e mantido em pimenteiras da cultivar Dedo-de-moça (Capsicum bacattum L.), mantidas em câmara com temperatura controlada para aproximadamente 18 e $20^{\circ} \mathrm{C}$, e fotoperíodo de 14 horas de luz e 10 horas de escuro. Previamente inoculadas com isolado proveniente de Botucatu-SP.

Todas as plantas utilizadas estavam em média com 60 dias de semeadura, e apresentavam altura média de 20 a $35 \mathrm{~cm}$. Para cada cultivar foram inoculas cinco plantas (Tabela 1). Estas foram inoculadas com uma suspensão de teliosporos aecidióides na concentração de $10^{4}$ esporos por $\mathrm{mL}^{-1}$ em água destilada e Tween a $0,01 \%$. A suspensão de esporos foi mantida a $12^{\circ} \mathrm{C}$ durante quatro horas no escuro para germinação dos teliosporos aecidióides (6). Após este período, a suspensão foi pulverizada, aproximadamente $5 \mathrm{~mL}$ por planta, utilizando um pulverizador manual de jardim.

Aos 9 e 12 dias da inoculação, as plantas já apresentavam os sintomas e alguns sinais da infecção foram avaliados. Nesse momento procedeu-se a espermatização, com auxílio de um pincel $\mathrm{n}^{\circ}$ 8, para promover o encontro dos talos geneticamente compatíveis e a formação dos soros aecidióides $(8,9)$.

Para analisar a ação do patógeno em cada planta, foi avaliada a severidade da infecção (SI) foi utilizada a metodologia de Castro et al. (2) com modificações. Foi contado o número de manchas cloróticas a cada $4 \mathrm{~cm}^{2}$ nos segundos e terceiros pares de folhas. A partir desses dados foi possível avaliar o número de manchas em cada $\mathrm{cm}^{2}$ de área foliar. Foram observadas as lesões (manchas cloróticas - sintomas) e não os espermogônios (sinais) formados, devido ao fato de que eles situam-se no centro das lesões, podendo cada uma conter até 3 espermogônios (Figura 2 - A, B, C, D, E).

A avaliação foi realizada medindo a intensidade da infecção entre 22 a 28 dias após a inoculação, empregando-se a escala de notas (Figura 1): reação de hipersensibilidade intensa (0) - não houve formação de teliossoros aecidióides e evolução da doença; reação de hipersensibilidade moderada (1) - presença de necrose, formação de poucos teliossoros aecidióides; poucos teliossoros aecidióides (2); quantidade moderada de teliossoros aecidióides (3); grande quantidade de teliossoros aecidióides (4); poucos teliossoros telióides (5); quantidade moderada de teliossoros telióides (6); grande quantidade de teliossoros telióides (7).

Nas avaliações, foi observado o surgimento de lesões cloróticas (sintomas) em ambas as faces das folhas, visíveis aos 9 a 12 dias da inoculação. As cultivares de C. annuum (cvs. Jalapeño e Ardida) apresentaram sintomas e sinais aos 9 dias da inoculação. Outras cultivares de C. annuum: os pimentões Martha-R, Dahra-R e Bruna-

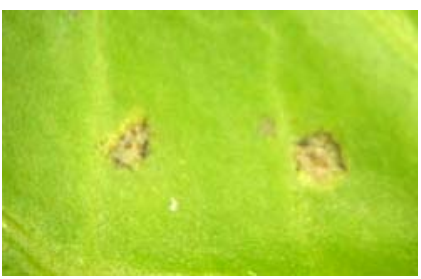

A. reação de hipersensibilidade intensa (0)

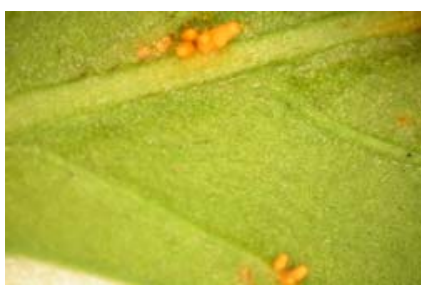

C. poucos teliossoros aecidióides (2)

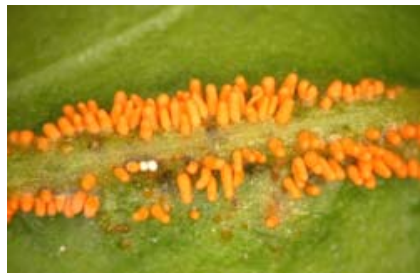

E. grande quantidade de teliossoros aecidióides (4)

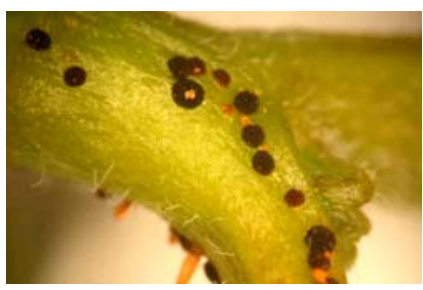

G. quantidade moderada de teliossoros telióides (6)

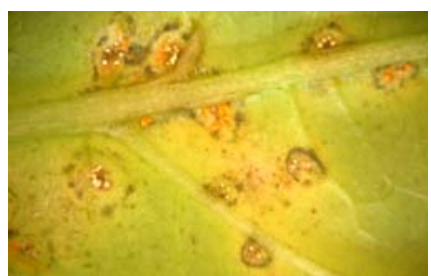

B. reação de hipersensibilidade moderada (1)

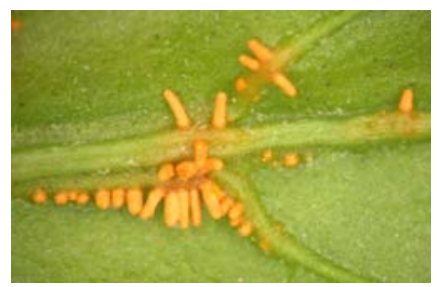

D. quantidade moderada de teliossoros aecidióides (3)

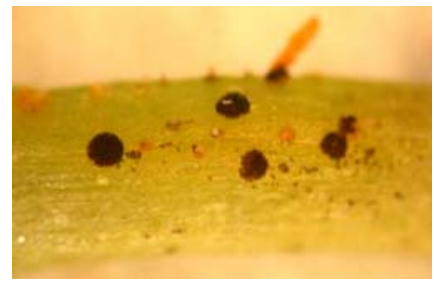

F. poucos teliossoros telióides (5)

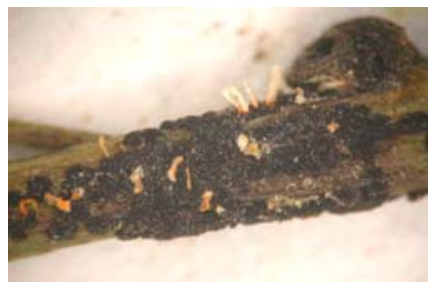

H. grande quantidade de teliossoros telióides (7)
Figura 1. Escala numérica da reação de hipersensibilidade, teliossoros aecidióides (A-E) e teliossoros telióides (F-H).

R e pimenta tomate, as lesões foram observadas aos 10 dias, e nas cultivares C. annuum (cv. Serrano), C. chinense (cv. Habañero), C. baccatum (cv. Chapéu-de-frade) e C.frutescens (cv. Malagueta) aos 12 dias da inoculação.

A severidade da infecção e a intensidade dos sintomas apresentados na figura 2, são observados na Tabela 2. As cultivares de Capsicum annuum apresentaram maior números de lesões com, exceção ao pimentão Dahra-R, e da pimenta cultivar Cayenne que apresentou reação de hipersensibilidade intensa nas folhas. Em cultivares com maior reação de hipersensibilidade foram observados os menores números de lesões.

Após o surgimento dos primeiros sintomas e sinais da doença, as plantas foram espermatizadas, para promover a interação entre os talos geneticamente compatíveis (9). Nas as cultivares com evolução da infecção, foi observada a formação dos teliossoros aecidióides nas folhas, nos ramos, órgãos florais e, a presença de superbrotamentos semelhantes aos sintomas comumente denominados "vassoura de bruxa". Algumas destas cultivares, como os pimentões produziram, frutos nos quais foi observado a presença de télios aecidióides, estes frutos originaram-se de órgãos florais já com a presença do fungo (Figura 2 - F, G, H). 
Tabela 1. Cultivares e espécies de solanáceas inoculadas com Puccinia pampeana. Severidade de Puccinia pampeana em cultivares de Capsicum sp. e outras solanáceas, com a contagem das lesões contendo espermogônios por $\mathrm{cm}^{2}$ e intensidade dos sintomas, nos segundos e terceiros pares de folhas.

\begin{tabular}{|c|c|c|c|c|}
\hline & & $\mathrm{SI} *\left(\mathbf{c m}^{2}\right)$ & INT & Médias \\
\hline \multirow{4}{*}{$\begin{array}{l}\text { Pimentas } \\
\text { (Capsicum spp.) }\end{array}$} & Pimenta tomate - "red ruffled" (C. annum L.)* & 14,4 & $4 ; 7$ & $3,86 \mathrm{~A}$ \\
\hline & Serrano (C. annuum L.)*** & 4,15 & $1 ; 3 ; 5$ & $2,16 \mathrm{C}$ \\
\hline & Cayenne (C. annuum L.) & 6,6 & 0 & $2,66 \mathrm{C}$ \\
\hline & Habañero (C. chinense L.)*** & 5,5 & 0 & $2,45 \mathrm{C}$ \\
\hline \multirow{3}{*}{$\begin{array}{l}\text { Pimentões } \\
\text { (Capsicum } \\
\text { annuum L.) }\end{array}$} & Martha-R** & 13,1 & $4 ; 6$ & $3,69 \mathrm{AB}$ \\
\hline & Dahra-R** & 6,5 & $4 ; 5$ & $2,65 \mathrm{C}$ \\
\hline & Bruna- $\mathrm{R}^{* *}$ & 11,75 & $4 ; 5$ & $3,5 \mathrm{AB}$ \\
\hline \multirow{2}{*}{ Outras solanáceas } & Berinjela (Solanum melongena L.)* & 0 & - & - \\
\hline & Jiló (Solanum gilo Raddi)* & & - & - \\
\hline
\end{tabular}

*Variedades provenientes de sementes/frutos adquiridos no mercado/**Cultivares provenientes de sementes doadas pela empresa Sakata seeds/sudamerica/ ***Cultivares provenientes de sementes doadas pelo Centro de Horticultura do Instituto Agronômico de Campinas. Média das cinco repetições. SI: severidade da infecção. INT: intensidade da infecção. Reação de hipersensibilidade intensa (0)/ Reação de hipersensibilidade moderada (1)/ Poucos teliossoros aecidióides (2)/ Quantidade moderada de teliossoros aecidióides (3)/ Grande quantidade de teliossoros aecidióides (4)/ Poucos teliossoros telióides (5)/ Quantidade moderada de teliossoros telióides (6)/ Grande quantidade de teliossoros telióides (7). Para a análise estatística os dados foram transformados em $\sqrt{\mathrm{x}+0,50}$. Médias seguidas da mesma letra não diferem entre si pelo teste de TUKEY. Coeficiente de variação 18,06 .

Das cultivares avaliadas, não houve evolução da doença em Capsicum annuun L. (pimenta cv. Cayenne) e Capsicum chinense L. (pimenta cv. Habañero). Embora tivessem apresentado os primeiros sintomas da doença, lesões no tecido contendo os espemogônios (Tabela 2), não ocorreu progresso da infecção, provavelmente devido ao mecanismo de defesa do hospedeiro ao patógeno: reação de hipersensibilidade. Ao redor dos espermogônios ocorreu significativa necrose dos tecidos, o que impede o desenvolvimento do patógeno (Figura 2 - I, J, K, L). Convém ressaltar que o isolado coletado em Botucatu e utilizado na inoculação, é proveniente de pimenta bode, também Capsicum chinense L.

Nas cultivares de pimentas cvs. Cayenne e Habañero, foi observada resistência, com intensa reação de hipersensibilidade, indicando a possibilidade destas serem empregadas para melhoramento genético e, possibilitar o desenvolvimento de cultivares de pimentas destinadas ao processamento industrial.

A ferrugem causada por Puccinia pampeana é específica do gênero Capsicum spp., entretanto, algumas cultivares podem apresentar mecanismos de defesa, como a reação de hipersensibilidade. Fungos e bactérias, podem ser bloqueados pelos tecidos necrosados, e morrerem rapidamente, devido à falta de nutrição. Este mecanismo de defesa é comum em fungos biotróficos (1).

As outras espécies de Capsicum avaliadas também apresentaram hipersensibilidade, mas de forma menos acentuada. Estas espécies foram C. annuum (pimenta cv. Serrano) e $C$. baccatum (pimenta cv. Chapéu-de-frade). Como pode ser observado na Figura 2 (M, N, O, P, Q, R), ocorreu o início da formação dos télios aecidióides, mas devido à necrose periférica da lesão, não houve o progresso da infecção. Embora tenha sido observada a reação de hipersensibilidade nas folhas, em hastes foi observado a formação dos teliossoros aecidióides e posteriormente teliossoros telióides, mostrando resistência parcial à ferrugem. Provavelmente, alguns dos télios aecidióides, pela falta de nutrição se tornaram inviáveis, apresentando coloração branca, e quando observados ao microscópio óptico, os teliosporos destes soros mostram-se desidratados e com formato irregular, e nos testes para germinação, o resultado foi negativo. Os teliosporos que ainda mostraram coloração amarelada típica apresentaram aspecto normal e ainda viáveis, o que seria, no habitat do fungo esta seria uma forma de sobrevivência, devido a possibilidade de dispersão.

É importante ressaltar que na cultivar de pimenta cv. Serrano, apesar de não haver formação de télios aecidióides nas folhas, houve superbrotamento (Figura 2 - S, T) e nestes, as folhas apresentaram a formação dos teliossoros aecidióides.

Uma hipótese para isto, seria devido à variabilidade genética, os esporos que foram depositados naquele ponto seriam mais infectivos, quando comparados aos que infectaram outras partes da plantas ou, outras plantas. Cada espermogônio formado após a infecção pelo basidiosporo possui informações genéticas diferentes devido à variabilidade genética. Cada teliosporo aecidióide resulta de uma recombinação genética, sendo uma multiplicação do ovo ou zigoto.

Quando da preparação de uma suspensão e da inoculação da planta, os teliosporos não são geneticamente iguais, devido a formação dos espermogônios, e após a espermatização, os télios aecidióides. Cada soro formado, apresenta uma nova recombinação genética, e assim cada télio aecidióide é diferente de outro, apesar de os teliosporos em um mesmo télio serem geneticamente iguais. Esta situação explica porque, para uma mesma espécie, algumas linhagens de fungos são mais infectivas do quando comparadas a outras que chegam mesmo a não provocar sintoma algum, nos mesmos hospedeiros.

Para estudos da variabilidade de Puccinia pampeana, deveria ser realizada uma inoculação inicial, com teliosporos provenientes de um único télio aecidióide.

As outras solanáceas, jiló e berinjela, inoculadas com $P$. pampeana, não apresentaram sintomas e sinais da doença, comprovando a especificidade desta ferrugem a Capsicum spp. Os resultados obtidos estão de acordo com os obtidos por Figueiredo \& Carvalho Jr. (3), que inocularam espécies de Capsicum em outros gêneros de solanáceas com $P$. pampeana, dentre elas três cultivares comerciais de berinjela, e observaram o desenvolvimento da doença em plantas de pimenta e pimentão.

Os resultados, permitem concluir que, apesar de algumas cultivares de Capsicum spp. apresentarem reação de hipersensibilidade, a ferrugem causada por $P$. pampeana é específica deste gênero. 


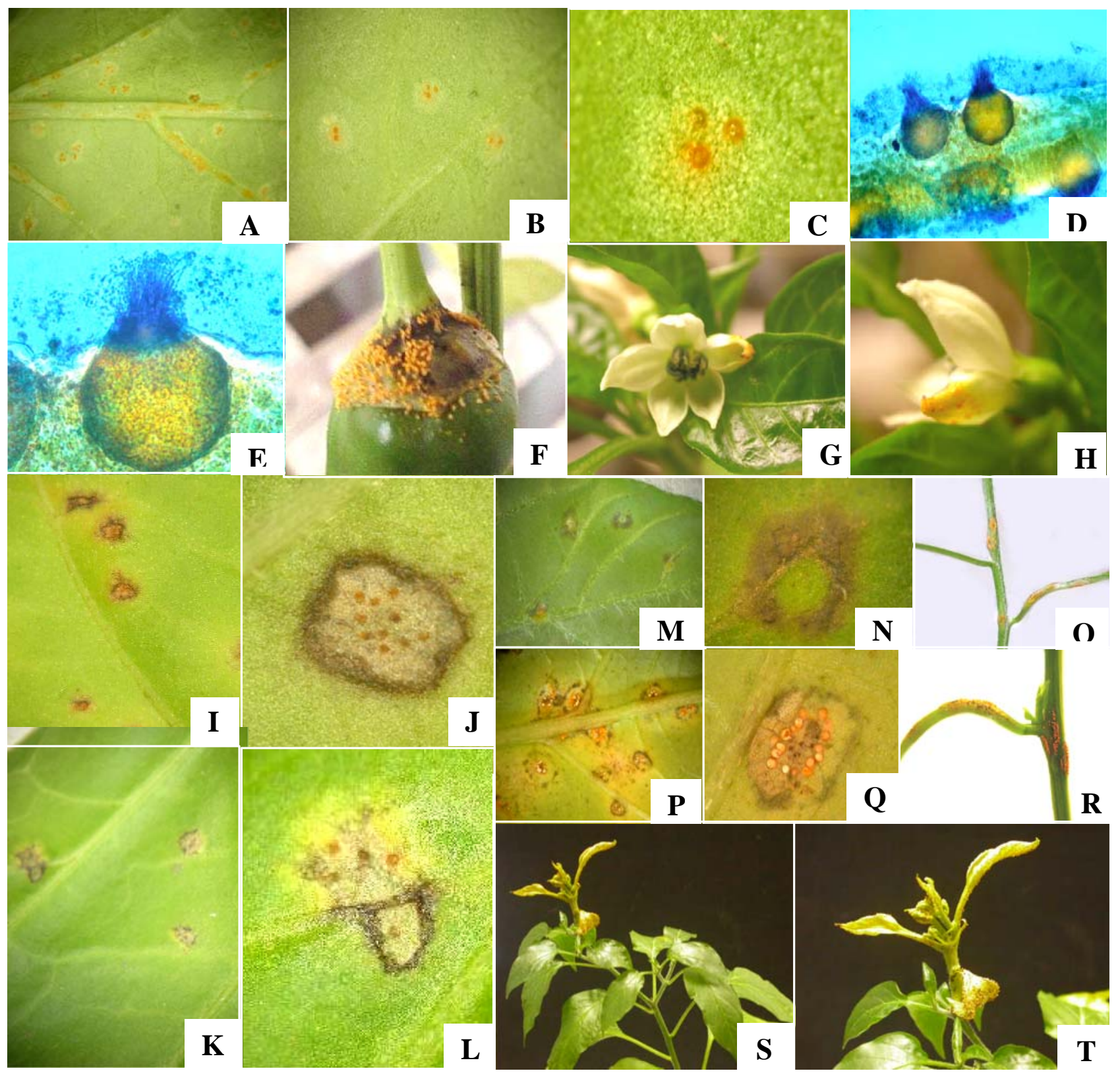

Figura 2. A - Lesões (sintomas) em folhas das cultivares inoculadas contendo os espermogônios de Puccinia pampeana (sinais) - face abaxial de folhas de Capsicum. B e C - lesões com mais de um espermogônio. D e E - corte de tecido vegetal apresentando espermogônio com hifas receptivas. F - Fruto de pimentão da cultivar Dahra-R com teliossoros aecidióides de Puccinia pampeana. G e H - Flor de pimentão da cultivar Bruna-R com teliossoros aecidióides de Puccinia pampeana nas pétalas. Reação de Hipersensibilidade apresentada pelas espécies de Capsicum: I e J - C. annuum (Pimenta Cayenne); K e L - C. chinense (Pimenta Habañero). Apesar da formação dos espermogônios de Puccinia pampeana, estes tornaram-se inviáveis devido à necrose do tecido foliar. Necrose ao redor dos espermogônios e hastes de pimenteiras inoculadas apresentando formação de teliossoros aecidióides de Puccinia pampeana. M, N e O - de C. annuum (pimenta serrano); P, Q e R - C. baccatum (pimenta Chapéu- de-frade). S e T Superbrotamento em planta de pimenta Serrano.

\section{REFERÊNCIAS BIBLIOGRÁFICAS}

1. Agrios, G.N. Plant Pathology. San Diego: Academic Press, 1995, p. 635.

2.Castro, H.A.; Krügnr; T.R.; Ideriha, C.H.F.; Capello, M.S.C.; Marchi, A.B. Inoculação cruzada de Eucalyptus, goiaba (Psidium guajava) e jambeiro (Syzygium jambos) com Puccinia psidii. Fitopatologia Brasileira, Brasília, v.8, p. 491-497, 1983.

3. Figueiredo, M.B; Carvalho Junior. Especificidade de Puccinia pampeana a Capsicum spp. Arquivos do Instituto Biológico, São Paulo, v. 22 supl., p. 3, 1991.
4.Figueiredo, M.B.; Carvalho Junior, A.A. Efeito da lavagem dos soros na germinação dos teliosporos telióides de Puccinia pampeana. Summa Phytopathologica, Jaboticabal, v.20, p. 101-104, 1994.

5.Figueiredo, M.B.; Carvalho Junior, A.A. Presença de um autoinibidor nos teliosporos telióides de Puccinia pampeana e o seu papel na sobrevivência da espécie. Summa Phytopatologica, Jaboticabal, v. 21, p. 200-205, 1995.

6. Figueiredo, M.B.; Pimentel, C.P.V.; Russomano, O.M.R.; Coutinho, L.N. Biologia da espécie biteliomórfica de Puccinia pampeana Speg.- Endophyllun pampeanum (Speg.) Lindq. ferrugem da pimenta e do pimentão (Capsicum spp.). Arqui- 
vos do Instituto Biológico, São Paulo, v. 54 (Supl.), p. 1$10,1987$.

7.Hennen, J. F.; Figueiredo, M.B.; Pimentel, C.P.V.; Russomanno, O.M.R. The life cycle and taxonomy of Puccinia pampeana (Speg.) Lindq. on Capsicum spp. and other Solanaceae. Reports of the Tottori Mycological Institute, Tottori, v. 22, p. 209-220, 1984.

8.Lopez-Franco, R.M.; Hennen, J.F.; Figueiredo, M.B. Development and sporogeny of the biteleomorphic species Puccinia pampeana on Capsicum spp. Fitopatologia Brasileira, Brasília, v. 15, p. 68-72, 1990.

9.Martins, E.M.F.; Carvalho Junior.; A.A.; Figueiredo, M.B. Relação entre Capsicum frutescens e os micélios mono e dicarióticos de Puccinia pampeana. Fitopatologia Brasileira, Brasília v. 20, p. 613-617, 1995.

10.Naqvi, S.S.M. Plant growth promoter and inhibitors. In: PESSARAKLI, M. (ed.). Handbook of plant and crop Physiology. New York: Marcel Dekker, 1990, 1004p. 